\title{
Polycomb group proteins: Novel molecules associated with ultraviolet A-induced photoaging of human skin
}

\author{
ZHUOXIA WU and LIANBO ZHANG \\ Department of Plastic and Reconstructive Surgery, China-Japan Union Hospital of Jilin University, \\ Changchun, Jilin 130033, P.R. China
}

Received June 13, 2016; Accepted April 13, 2017

DOI: $10.3892 /$ etm.2017.4807

\begin{abstract}
Epigenetic repressor polycomb group (PcG) proteins are thought to serve a role in a number of cellular processes, including carcinogenesis, senescence, apoptosis and DNA repair. In the present study, long-wave ultraviolet A (UVA) was used to irradiate human skin fibroblasts (HSFs) and embryonic skin fibroblasts (ESFs) in order to simulate photoaging of the skin. The results of cell proliferation, apoptosis, hyaluronic acid (HA) content and reverse transcription-quantitative polymerase chain reaction assays revealed that the expression levels of genes encoding key PcG proteins (BMI-1 and EZH2) were altered. In addition, the expression levels of these genes were associated with the expression of enzymes that regulate HA synthesis. Furthermore, the expression levels of PcG proteins differed between HSFs and ESFs, suggesting that PcG proteins serve a role in altering HA synthesis during the UVA-induced fibroblast aging process. This signaling pathway may represent a novel molecular mechanism regulating the photoaging of the skin. The findings of the present study provide important insights into the underlying mechanisms of photoaging of the human skin. Further studies are required to clarify the molecular mechanisms underling skin aging and to identify targets for the clinical treatment of photoaging.
\end{abstract}

\section{Introduction}

The skin is the body's largest sensory organ, covering the majority of the body. The primary function of the skin is the protection of body tissues and organs from physical and mechanical damage, toxic chemicals and pathogenic microorganisms; therefore, the skin is subjected to various factors that cause aging of the tissue. In addition to the body's natural aging processes, exogenous optical radiation directly promotes

Correspondence to: Dr Lianbo Zhang, Department of Plastic and Reconstructive Surgery, China-Japan Union Hospital of Jilin University, 126 Xiantai Street, Changchun, Jilin 130033, P.R. China E-mail: lianbozhangdoc@163.com

Key words: photoaging polycomb group, ultraviolet A, human skin fibroblast, human embryonic skin fibroblast, hyaluronic acid skin aging. Among the various types of light affecting the skin, ultraviolet A (UVA) is the primary contributor to skin photoaging because it is not absorbed by any laminar flow and potently penetrates the skin $(1,2)$. Previous studies have demonstrated that the probability of skin aging is doubled in populations with high UV exposure compared with populations with lower exposure, and skin aging occurs $\leq 10$ years earlier in such populations (3-5).

Common features of skin aging include a rough texture, dryness, reduced elasticity and wrinkles, and these features are associated with a reduction of the extracellular matrix in the skin dermis (6). Hyaluronic acid (HA), which is synthetized and secreted by the fibroblasts in the skin dermis, is an important molecule because of its strong hydrophilicity. HA controls the water content, swelling and diffusion gradient in the skin and therefore functions to maintain its structural integrity (7-9). The primary treatment to prevent or alleviate skin aging is the injection of exogenous HA (10). However, due to the rapid absorption and metabolism of HA, these treatments do not provide long-term effects. In order to slow down the process of skin aging, the underlying molecular mechanism of the reduction in HA during skin aging requires elucidation.

$\mathrm{HA}$ is a glycosaminoglycan that is synthetized and secreted by fibroblasts. The rate of synthesis, stability, extensibility and total amount of HA are dynamically regulated by hyaluronan synthases 1-3 (HAS 1-3), and hyaluronate lyases 1 and 2 (HYAL1 and HYAL2) (11). HAS and HYAL proteins serve different roles in the synthesis of HA, and differentially regulate $\mathrm{HA}$ in response to stimulation by different types of cytokines (12). Embryonic fibroblasts (EFs) are considered the youngest fibroblasts present in the body; A previous study indicated that the $H A S$ gene is differently expressed in fibroblasts during different phases of embryonic development (13). In addition, HA is differentially synthesized in human embryonic skin fibroblasts (ESFs) and human skin fibroblasts (HSFs) (14), suggesting that HAS 1-3, HYAL1 and HYAL2 serve unique and different roles in human growth, development and aging. Therefore, HSFs and ESFs were used as model cells in the present study.

The present study aimed to further investigate and elucidate the underlying molecular mechanisms regulating the synthesis of HA in fibroblasts. Multiple researchers have examined the mechanisms regulating the synthesis of HA in fibroblasts (15-17). From these studies, two mechanisms have 
been confirmed; the activation of the transforming growth factor $\beta$ receptor (TGF- $\beta \mathrm{R}) /$ Smad 2 and HA-mediated cluster of differentiation 44-epidermal growth factor receptor (EGFR) colocalization and signaling (15-17). The shared extracellular signals of these two mechanisms are able to regulate the activity of extracellular signal-regulated kinase 1/2 (ERK1/2) (15-17). However, the underlying regulatory mechanisms of HA synthesis at the epigenetic level in skin aging remain unclear. Accordingly, the present study aimed to identify epigenetic regulatory molecules that may be associated with photoaging of the skin, with the goal of identifying novel regulatory signaling pathways.

Polycomb group $(\mathrm{PcG})$ proteins are chromatin-modifying proteins that serve important roles as transformational global epigenetic repressors in cell proliferation, senescence and tumorigenesis (18). PcG proteins include two core protein complexes, polycomb repressive complex 1 and 2 (PRC1 and PRC2). PRC1 is predominantly responsible for maintaining the stability of chromatins that are in a repressive state, and PRC2 functions during the initiation phase of cellular transcriptional repression $(19,20)$. The core subunit of PRC2, enhancer of zeste homolog 2 (EZH2), and the polycomb complex protein BMI-1 (BMI-1) in PRC1, are the most well studied PcG proteins. PcG proteins have been demonstrated to be associated with the regulation of hematopoietic stem cell aging; however, few studies have investigated the regulation of fibroblasts in regards to photoaging of human skin. Therefore, the present study investigated whether $E Z H 2$ and $B M I-1$ serve a role in regulating the synthesis of HA during UVA irradiation-induced skin photoaging, and to examine whether the role of HA differs in ESFs and HSFs. These data are expected to aid in the identification of novel regulatory signaling pathways underlying skin photoaging and to elucidate effective therapeutic targets.

\section{Materials and methods}

Cell culture. HSFs were purchased from Shanghai EK-Bioscience Co., Ltd. (Shanghai, China) and ESFs were purchased from Shanghai Xinyu Biological Technology Co., Ltd. (Shanghai, China). Cells were cultured as monolayers in high glucose Dulbecco's modified Eagle's medium (DMEM, high glucose; Gibco; Thermo Fisher Scientific, Inc., Waltham, MA, USA) supplemented with $10 \%$ fetal bovine serum (FBS; Sciencell Research Laboratories, Inc., Carlsbad, CA, USA) and 1\% penicillin-streptomycin (Gibco; Thermo Fisher Scientific, Inc.) in $25 \mathrm{ml}$ culture flasks at $37^{\circ} \mathrm{C}$ with $5 \% \mathrm{CO}_{2}$. Cells were seeded in 96 -well plates to a density of $8 \times 10^{3} /$ well in cell viability assay and detection of HA content due to the requirements of an ELISA kit for HA (cat. no. CEA182Ge; Cloud-Clone Corp., Katy, TX, USA), and in other detections cells were seeded in 6 -well plates to a density of $2 \times 10^{5} /$ well.

UVA irradiation. A ZF-1 Tri-Ultraviolet Analyzer (Jiangsu Qilin-Lab Co., Haimen, China) was used to produce UVA radiation at a wavelength of $365 \mathrm{~nm}$. A UV radiation meter (Kühnast Strahlungstechnik GmbH, Wächtersbach, Germany) was used to detect the real-time ultraviolet irradiance; the radiation distance was set as $<5 \mathrm{~cm}$ to prevent decay. At $24 \mathrm{~h}$ after seeding $\left(8 \times 10^{3} /\right.$ well $)$ the cells were subjected to
UVA irradiation using the designed radiation dose $(0,1,4$ and $8 \mathrm{~J} / \mathrm{cm}^{2}$ ). The present study reviewed previous studies on UVA-induced skin aging and the UVA dose in the establishment of aging model range from $7.5 \mathrm{~J} / \mathrm{cm}^{2}$ to $15 \mathrm{~J} / \mathrm{cm}^{2}(21-27)$, the majority of which selected $10 \mathrm{~J} / \mathrm{cm}^{2}$. In Huimin's (27) study on the effect of ultraviolet radiation on the proliferation of human fibroblasts, cells were irradiated with ten doses of $1-10 \mathrm{~J} / \mathrm{cm}^{2}$. The results suggested that the inhibitory dose (ID) of $50 \%$ was $4 \mathrm{~J} / \mathrm{cm}^{2}$ and the inhibition rate of the $10 \mathrm{~J} / \mathrm{cm}^{2}$ group was $85 \%$. In order to establish a suitable aging model, the present study selected $8 \mathrm{~J} / \mathrm{cm}^{2}$ as the high dose group, $4 \mathrm{~J} / \mathrm{cm}^{2}$ as the medium dose group, and $1 \mathrm{~J} / \mathrm{cm}^{2}$ as the low dose group. The irradiation time was calculated based on the selected irradiation dose as follows: UVA $\left(\mathrm{J} / \mathrm{cm}^{2}\right)=$ irradiance $\left(\mathrm{W} / \mathrm{cm}^{2}\right) \mathrm{x}$ time $(\mathrm{sec})$.

Establishment of a UVA-induced aging model. When the cells reached a density of $6 \times 10^{5}$ cells/flask, HSFs and ESFs were detached by trypsinization and then centrifuged at $160 \mathrm{x}$ g at $4^{\circ} \mathrm{C}$ for $5 \mathrm{~min}$. Cells were then resuspended in the DMEM culture medium, with $10 \% \mathrm{FBS}$ at $37^{\circ} \mathrm{C}$ and $5 \% \mathrm{CO}_{2}$. The cells were counted manually using a hemocytometer and an optical light microscope (Olympus Corporation, Tokyo, Japan) and each well in the 96-well plate was seeded with 8,000 cells (23-27) for inoculation into cell culture plates. The two types of cells were then divided into the following groups: Experimental group (EG; cells in culture medium, irradiated), the control group (CG; cells in culture medium, nonirradiated), the blank experimental group (BE; no cells, irradiated) and the blank control group (BC; no cells, nonirradiated). Each group was analyzed in triplicate and sterile saline was added around each well to prevent evaporation. After overnight culture and adherence to the wells, the cells were exposed to UVA irradiation at four doses $\left(0,1,4\right.$ or $\left.8 \mathrm{~J} / \mathrm{cm}^{2}\right)$ using the ZF-1 Tri-Ultraviolet Analyzer at $365 \mathrm{~nm}$. The cells were cultured at $37^{\circ} \mathrm{C}$ with $5 \%$ $\mathrm{CO}_{2}$ and analyzed using flow cytometry, as described in detection of apoptosis, an Epoch Microplate Spectrophotometer, as described in Cell Proliferation assay (BioTek Instruments, Inc., Winooski, VT, USA) and Real-Time PCR. SPSS statistical software, version 13.0 (SPSS, Inc., Chicago, IL, USA) was used at 0,12 and $24 \mathrm{~h}$ after the irradiation.

Cell proliferation assay. A total of $20 \mu \mathrm{l}$ of Cell Counting Kit- 8 (CCK-8; Dojindo Molecular Technologies, Inc., Kumamoto, Japan) assay solution was added to each well under sterile conditions, followed by gentle shaking to mix the contents of the plates. The absorbance at $450 \mathrm{~nm}$ was then measured with an Epoch microplate spectrophotometer (BioTek Instruments, Inc.) at $25^{\circ} \mathrm{C}$ after $0,0.5,1,2$ and $3 \mathrm{~h}$ using a microplate reader. Cell proliferation curves were drawn using data from the time points when the cells were the most potent and stably stained, as this indicates living cells. The effect of the different radiation doses on the proliferation of the two cells types was then analyzed and compared. The cell proliferation activity of the control was calculated as follows: (EG-BE)/(CG-BC).

Detection of apoptosis. After digestion with EDTA-free trypsin and termination of the digestion, HSFs and ESFs were washed with PBS and transferred into $5 \mathrm{ml}$ tubes. The cells were centrifuged at $566 \times \mathrm{g}$ at $4^{\circ} \mathrm{C}$ for $5 \mathrm{~min}$, the supernatant 
Table I. Primer sequences for reverse transcription-quantitative polymerase chain reaction analysis.

\begin{tabular}{lll}
\hline Gene & \multicolumn{1}{c}{ Primer sequence } & Direction \\
\hline HAS1 & 5'-TACAACCAGAAGTTCCTGGG-3' & Forward \\
& 5'-CTGGAGGTGTACTTGGTAGC-3' & Reverse \\
HAS2 & 5'-GTGGATTATGTACAGGTTTGTGA-3' & Forward \\
& 5'-TCCAACCATGGGATCTTCTT-3' & Forward \\
HAS3 & 5'-GAGATGTCCAGATCCTCAACAA-3' & Reverse \\
HYAL1 & 5'-CCCACTAATACACTGCACAC-3' & Forward \\
HYAL2 & 5'-CCAAGGAATCATGTCAGGCCATCAA-3' & Reverse \\
BMI-1 & 5'-CCCACTGGTCACGTTCAGG-3' & Forward \\
& 5'-GGCTTAGTGAGATGGACCTC-3' & Reverse \\
EZH2 & 5'-CCGTGTCAGGTAATCTTTGAG-3 & Forward \\
GAPDH & 5'-TGGATCGGAAAGTAAACAAAGAC-3' & Reverse \\
& 5'-TGCATCACAGTCATTGCTGCT-3' & Forward \\
& 5'-ATGCGACTGAGACAGCTCAA-3' & Reverse \\
& 5'-TGGGATGACTTGTGTTGGAA-3' & Forward \\
& 5'-GTGAAGGTCGGAGTCAACG-3' & Reverse
\end{tabular}

HYAL, hyaluronidase; $H A S$, hyaluronan synthase; $E Z H 2$, enhancer of zeste homolog 2; BMI-1, polycomb complex protein $B M I-1$.

was discarded and the cells were resuspended, filtered and washed with PBS. This process was repeated twice. An Annexin V-fluorescein isothiocyanate (FITC)/propidium iodide (PI) kit (cat. no. KGA105; Nanjing Keygen BioTech Co., Ltd., Nanjing, China) and a flow cytometer (BD FACSARIA; BD Biosciences, Franklin Lakes, NJ, USA) were then used to detect apoptotic cells, which were used according to the manufacturer's protocol: $2.0 \times 10^{5}$ cells and $2 \mathrm{ml}$ culture medium were added to each well of six-well plates, triplicate wells were performed for each experimental group. After cells were adherent for $24 \mathrm{~h}$, different doses of irradiation were administered $\left(0,1,4\right.$ and $\left.8 \mathrm{~J} / \mathrm{cm}^{2}\right)$. Cells and flow tubes were collected and $100 \mu \mathrm{l}$ buffer was added to resuspend cells within each tube, filtered through filter paper to ensure that the cells were single state. Then, $50 \mu 1$ Annexin V-FITC dilution and $50 \mu 1 \mathrm{PI}$ dilution were added to each tube. The tubes were placed in the dark at room temperature for $15 \mathrm{~min}$. Detection was performed using flow cytometry, the excitation wavelength (Ex) was $E x=488 \mathrm{~nm}$, emission wavelength $(\mathrm{Em})$ was $E m=530 \mathrm{~nm}$.

Detection of HA content. An ELISA kit for HA (cat. no. CEA182Ge; Cloud-Clone Corp., Katy, TX, USA) was used to detect the HA content of the HSFs and ESFs according to the manufacturer's protocol. Briefly, the standard (from the kit), sample (Sample to be measured) and control wells (Reagent Diluent from the kit) were produced and their optical density at $450 \mathrm{~nm}$ was measured using a microplate reader.

Reverse transcription-quantitative polymerase chain reaction (RT-qPCR) analysis. Total RNA was isolated using TRIzol reagent (Invitrogen; Thermo Fisher Scientific, Inc., Waltham, MA, USA) according to the manufacturer's protocol and quantified spectrophotometrically. A RevertAid First Strand cDNA Synthesis kit (cat. no. K1622; Thermo Fisher Scientific, Inc.) was used for the generation of cDNA according to the manufacturer's protocol. The thermocycling conditions were as follows: $42^{\circ} \mathrm{C}$ for $60 \mathrm{~min} ; 70^{\circ} \mathrm{C}$ for $5 \mathrm{~min}$; and maintenance at $4^{\circ} \mathrm{C}$. A PrimeScript ${ }^{\mathrm{TM}}$ RT Reagent kit with gDNA Eraser (Perfect Real Time; cat. no. RR047A; Takara Bio Inc., Kusatsu, Japan) was used according to the manufacturer's protocol with a CFX Real-Time PCR Detection system (Bio-Rad Laboratories, Inc., Hercules, CA, USA) for qPCR. The thermocycling conditions were as follows: Initial denaturation at $95^{\circ} \mathrm{C}$ for $3 \mathrm{~min}$; and 45 cycles of denaturation at $95^{\circ} \mathrm{C}$ for $15 \mathrm{sec}$, annealing at $5^{\circ} \mathrm{C}$ for $20 \mathrm{sec}$ and extension at $72^{\circ} \mathrm{C}$ for $30 \mathrm{sec}$. The GAPDH gene was used as the internal reference, and the $2^{-\Delta \Delta \mathrm{Cq}}$ relative quantification method (28) was used to calculate and analyze the mRNA expression levels of the target genes and selected proteolytic-cleavage products. The qPCR primer sequences are presented in Table I.

Statistical analysis. Data were analyzed using Dunnett's test with SPSS software (version 13.0; SPSS, Inc., Chicago, IL, USA). Data are presented as the mean \pm standard deviation of triplicate experiments. $\mathrm{P}<0.05$ was considered to indicate a statistically significant difference.

\section{Results}

HSF and ESF proliferation is altered by UVA irradiation. Microscopic observations demonstrated that the morphologies of HSFs and ESFs exhibited several differences. Specifically, the HSFs (Fig. 1A) were relatively more elongated and regularly spindle-shaped, whereas the ESFs (Fig. 1B) were relatively flatter, larger and more irregular. The results of the CCK- 8 assay demonstrated that HSF proliferation in the $1 \mathrm{~J} / \mathrm{cm}^{2}$ group increased over time, whereas the proliferation rate of HSFs in the 4 and $8 \mathrm{~J} / \mathrm{cm}^{2}$ groups tended to decrease with time (Fig. 1C). This suggests that lower UVA doses promote HSF proliferation and that increasing doses 
A

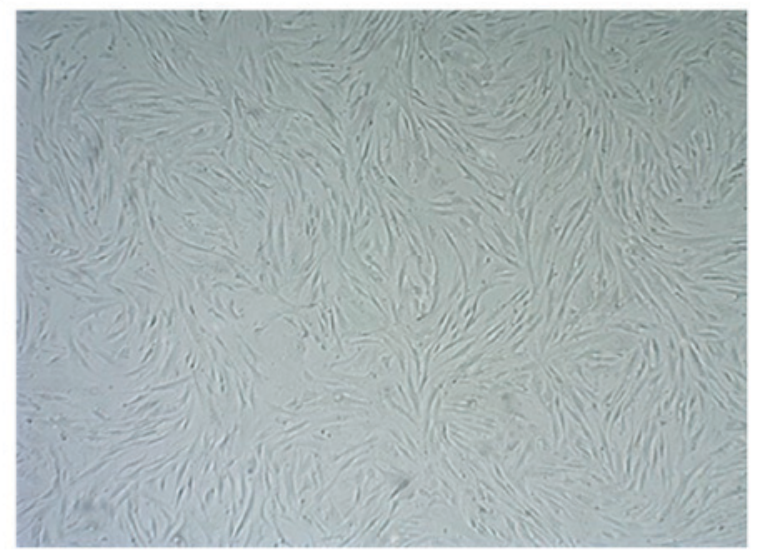

C

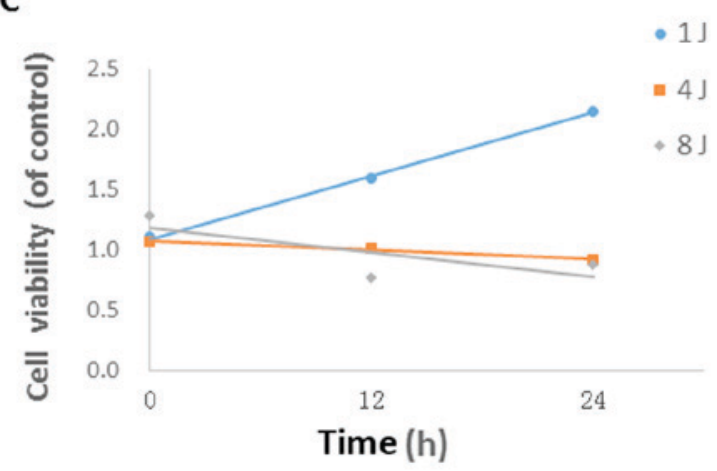

B

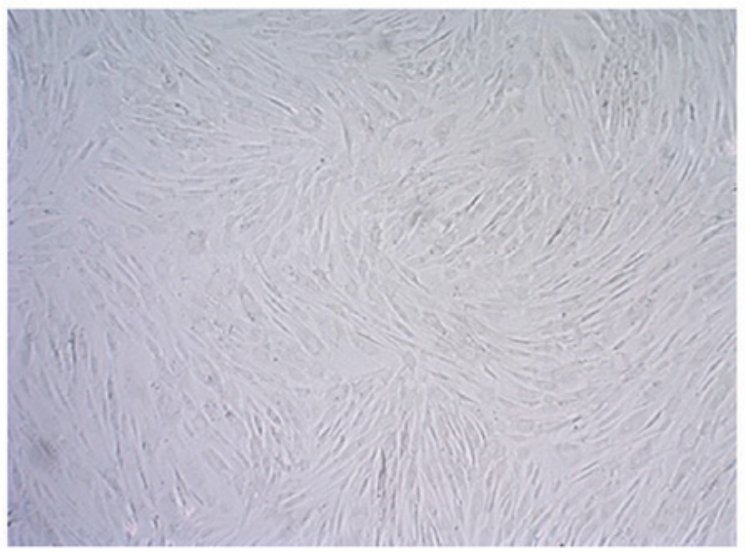

D

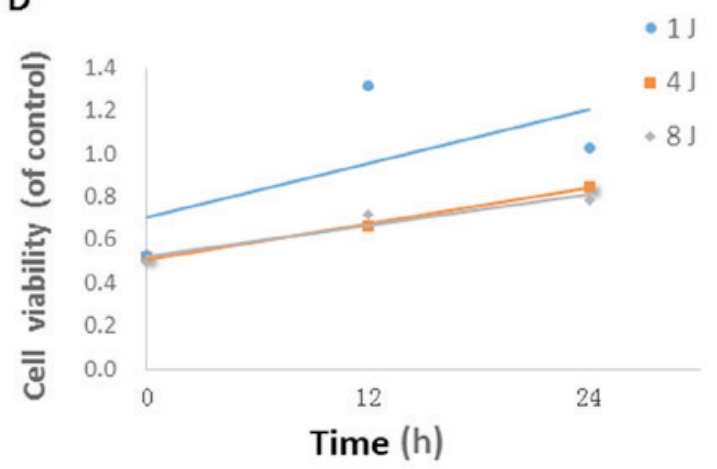

Figure 1. HSF and ESF proliferation is altered by UVA irradiation. Morphological differences between (A) HSFs and (B) ESFs. Magnification, x60. HSFs were relatively more elongated and regularly spindle, whereas ESFs were flatter and more irregular in shape. Impacts of different UVA radiation doses on the proliferative rates of (C) HSFs and (D) ESFs via the cell counting kit- 8 assay. HSFs, human skin fibroblasts; ESFs, embryonic skin fibroblasts; UVA, ultraviolet A.

inhibit HSF proliferation. For ESFs, at $0 \mathrm{~h}$ after irradiation the cell proliferation rate of all irradiated groups was $<1$ compared with the control (Fig. 1D). Additionally, higher UVA doses were associated with lower proliferation rates compared with lower doses, suggesting that higher doses of UVA irradiation inhibit ESF proliferation (Fig. 1D). However, as the time after irradiation increased, the cell proliferation activity gradually increased in each group (Fig. 1D).

Apoptotic rate of HSFs and ESFs following UVA irradiation. Flow cytometry analysis indicated that the apoptotic and necrotic HSF populations were increased in the 1 and $4 \mathrm{~J} / \mathrm{cm}^{2}$ groups compared with those in the control group (Fig. 2A and B). Additionally, the percentage of apoptotic and necrotic HSFs in the $4 \mathrm{~J} / \mathrm{cm}^{2}$ group was higher compared with those in the $1 \mathrm{~J} / \mathrm{cm}^{2}$ group, whereas those in the $8 \mathrm{~J} / \mathrm{cm}^{2}$ group were lower compared with those in the $4 \mathrm{~J} / \mathrm{cm}^{2}$ group (Fig. 2A and $\mathrm{B}$ ) and the results tended to indicate that each dose group was consistent at different time points, compared with the control group (Fig. 2A and B). The percentage of apoptotic and necrotic ESFs were increased in a dose-dependent manner after UVA irradiation, with the percentages in the $8 \mathrm{~J} / \mathrm{cm}^{2}$ group being the largest (Fig. 2C and D).

Alteration in HA content of HSFs and ESFs after UVA irradiation. The HA content of HSFs and ESFs was decreased in each UVA-dose irradiated comparing with the control group, with the exception of ESFs irradiated with $1 \mathrm{~J} / \mathrm{cm}^{2}$ for $24 \mathrm{~h}$
(Fig. 3). In addition, the HA content of HSFs was markedly higher compared with that in ESFs irradiated with the same dose of UVA and at the same time point.

UVA irradiation alters $m R N A$ expression of HAS1-3, HYAL1 and HYAL2 in HSFs and ESFs. The results of RT-qPCR analysis revealed that in HSFs HASI mRNA levels were significantly upregulated after $1 \mathrm{~J} / \mathrm{cm}^{2}$ UVA irradiation, but significantly reduced in the 4 and $8 \mathrm{~J} / \mathrm{cm}^{2}$ groups, compared with the $0 \mathrm{~J} / \mathrm{cm}^{2}$ group (all $\mathrm{P}<0.05$; Fig. $4 \mathrm{~A}$ ). In ESFs, HAS1 mRNA level at all irradiation doses was below the minimum detection level (Fig. 4A). Additionally, the expression of HAS2 mRNA was upregulated by UVA irradiation in a dose-dependent manner in HSFs (Fig. 4B). However, in ESFs HAS2 mRNA expression decreased in a dose-dependent manner with UVA irradiation (Fig. 4B). The expression of HAS3 mRNA in HSFs was upregulated in all irradiation groups compared with the $0 \mathrm{~J} / \mathrm{cm}^{2}$ group, among which the upregulation in the $1 \mathrm{~J} / \mathrm{cm}^{2}$ group was significantly increased $(\mathrm{P}<0.05$; Fig. $3 \mathrm{C})$. Conversely, in ESFs, HAS3 mRNA expression was downregulated in all irradiation groups (Fig. 4C). HYAL1 mRNA expression levels were upregulated as the dose of UVA radiation increased in HSFs and ESFs (Fig. 4D). Compared with the $0 \mathrm{~J} / \mathrm{cm}^{2}$ group, HYAL2 mRNA expression was upregulated in HSFs in the $1 \mathrm{~J} / \mathrm{cm}^{2}$ group and significantly unregulated in the $4 \mathrm{~J} / \mathrm{cm}^{2}$ group, but significantly downregulated in the $8 \mathrm{~J} / \mathrm{cm}^{2}$ group (all $\mathrm{P}<0.05$; Fig. 4E). By contrast, in ESFs, 

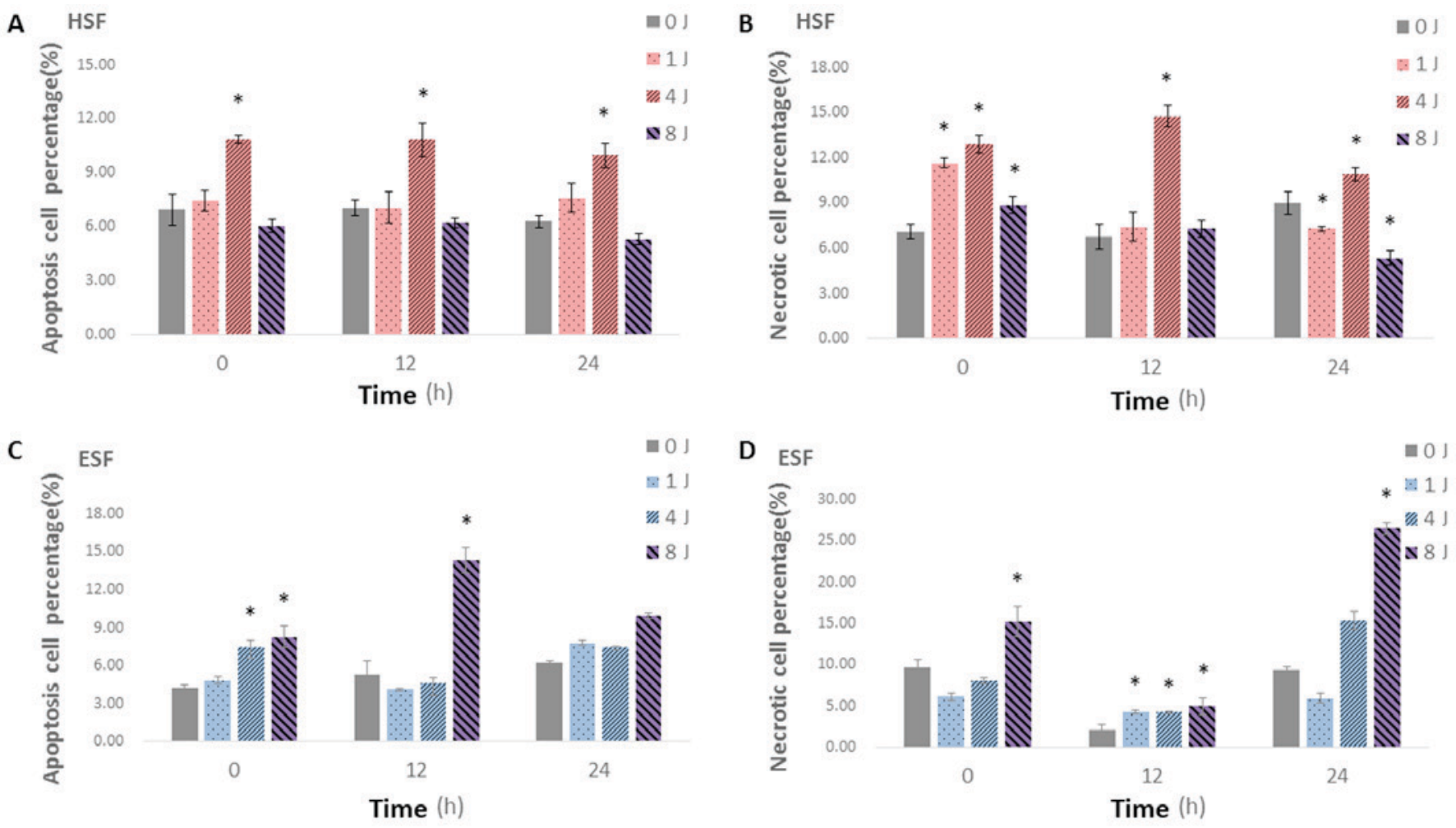

Figure 2. Apoptotic rate of HSFs and ESFs following UVA irradiation. Impacts of different UVA radiation doses on the (A) apoptosis and (B) necrosis of HSFs, and (C) apoptosis and (D) necrosis of ESFs. ("P<0.05 vs. $0 \mathrm{~J} / \mathrm{cm}^{2}$ ). HSFs, human skin fibroblasts; ESFs, embryonic skin fibroblasts; UVA, ultraviolet A.
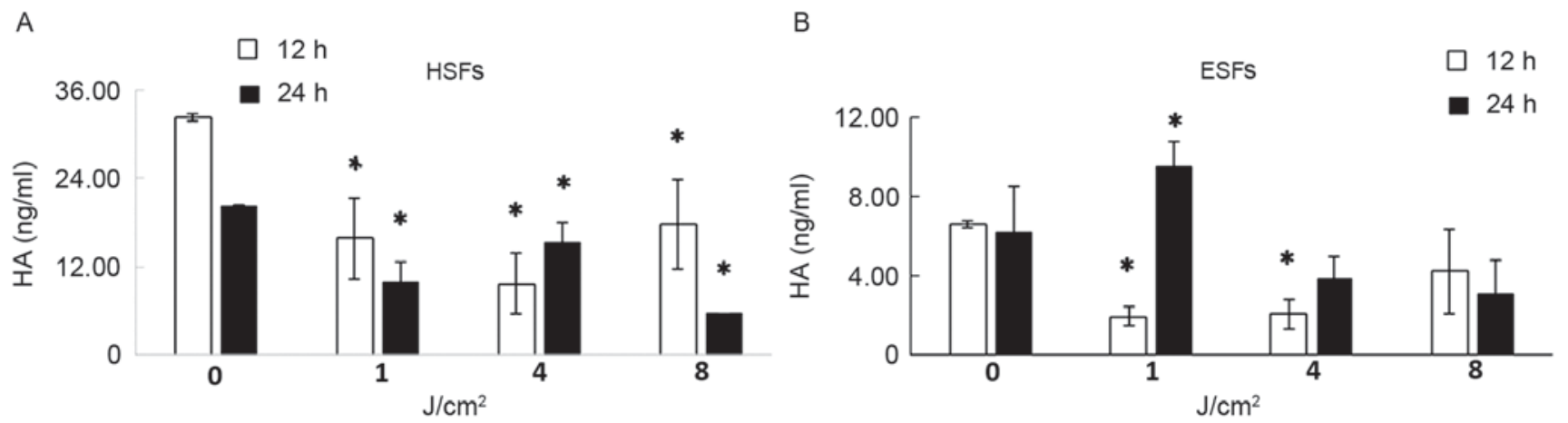

Figure 3. Alteration in HA content of HSFs and ESFs after UVA irradiation. The HA content of (A) HSFs and (B) ESFs after irradiation with UVA for 12 and 24 h. "P<0.05. HA, hyaluronic acid; HSFs, human skin fibroblasts; ESFs, embryonic skin fibroblasts; UVA, ultraviolet A.

HYAL2 mRNA expression levels were significantly upregulated in the $1 \mathrm{~J} / \mathrm{cm}^{2}$ group, but significantly downregulated in the 4 and $8 \mathrm{~J} / \mathrm{cm}^{2}$ groups, compared with the $0 \mathrm{~J} / \mathrm{cm}^{2}$ group (all $\mathrm{P}<0.05$; Fig. 4E).

HSF and ESF expression of BMI-1 and EZH2 mRNA is modified by UVA irradiation. The RT-qPCR analysis results demonstrated that there were no significant differences in BMI-1 and EZH2 mRNA expression levels in HSFs in the 1 and $4 \mathrm{~J} / \mathrm{cm}^{2}$ groups compared with the $0 \mathrm{~J} / \mathrm{cm}^{2}$ group (Fig. 5). However, HSF mRNA levels of BMI-1 and EZH-2 were significantly upregulated in the $8 \mathrm{~J} / \mathrm{cm}^{2}$ group compared with the $0 \mathrm{~J} / \mathrm{cm}^{2}$ group $(\mathrm{P}<0.05$; Fig. 5). By contrast, in ESFs, the expression of BMI-1 and EZH2 mRNA after UVA irradiation in all groups exhibited no statistical difference, compared with the $0 \mathrm{~J} / \mathrm{cm}^{2}$ group (Fig. 5).

\section{Discussion}

Features of skin photoaging caused by long-term UVA irradiation, including wrinkle formation and reduced elasticity, are induced by changes in various molecules due to damage to dermal fibroblasts (29). Previous studies have indicated that UVA-induced skin photoaging involves a variety of signal transduction molecules and pathways, including the generation of reactive oxygen species (ROS), activation of protein kinase signaling pathways, expression and activation of metalloproteinases, and induction of epidermal growth factor expression (30-32). Photoaging of the skin at the epigenetic level remains unclear. As a transformational global epigenetic repressor, $\mathrm{PcG}$ proteins serve important roles in proliferation, senescence, tumorigenesis and other cellular processes $(33,34)$; therefore, $\mathrm{PcG}$ proteins may be associated with UVA-induced 
A

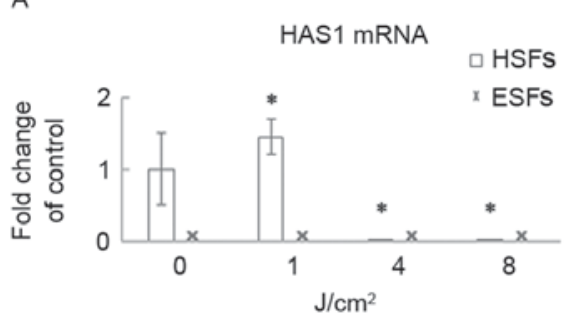

D

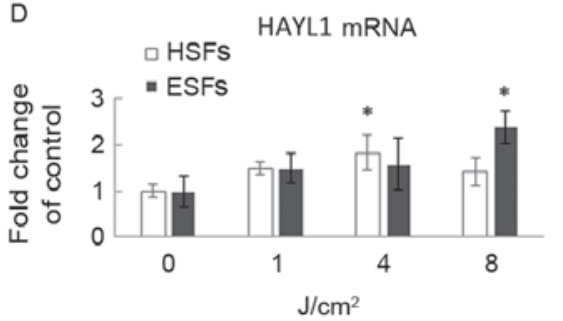

B

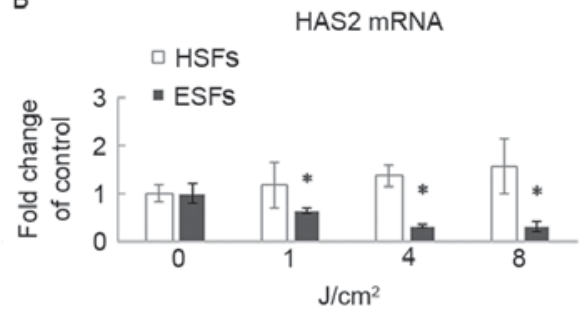

E

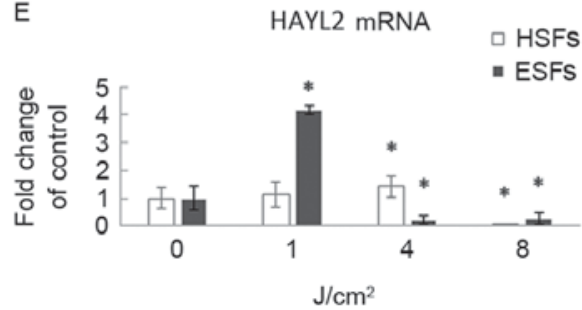

C

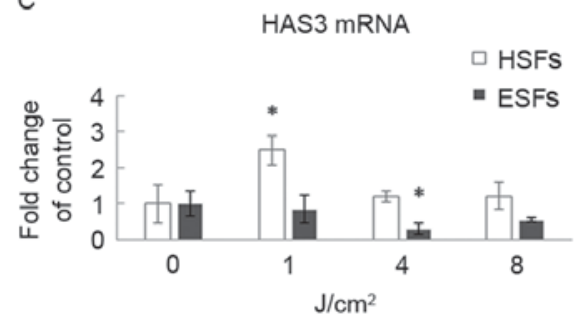

Figure 4. UVA irradiation alters mRNA expression of HAS1-3, HYAL1 and HYAL2 in HSFs and ESFs. Relative mRNA expression levels of (A) HAS1, (B) HAS2 and (C) HAS3 in HSFs and ESFs irradiated with UVA. Relative mRNA expression levels of (D) HYAL1 and (E) HYAL2 "P<0.05. UVA, ultraviolet A; $H Y A L$, hyaluronidase; $H A S$, hyaluronan synthase; HSFs, human skin fibroblasts; ESFs, embryonic skin fibroblasts.

A

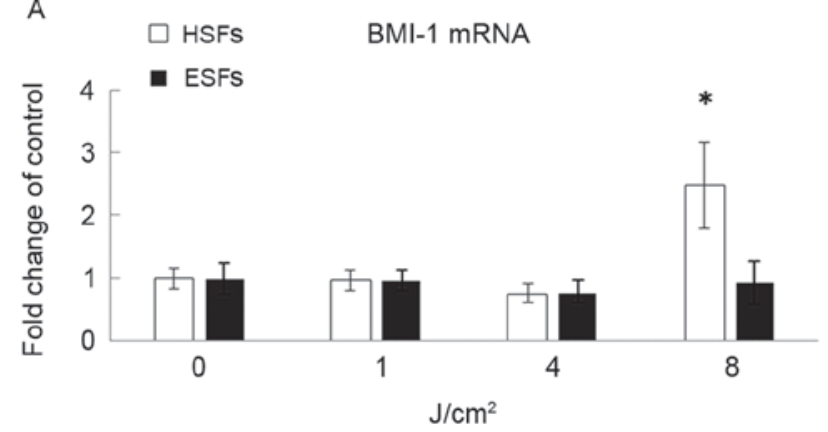

B

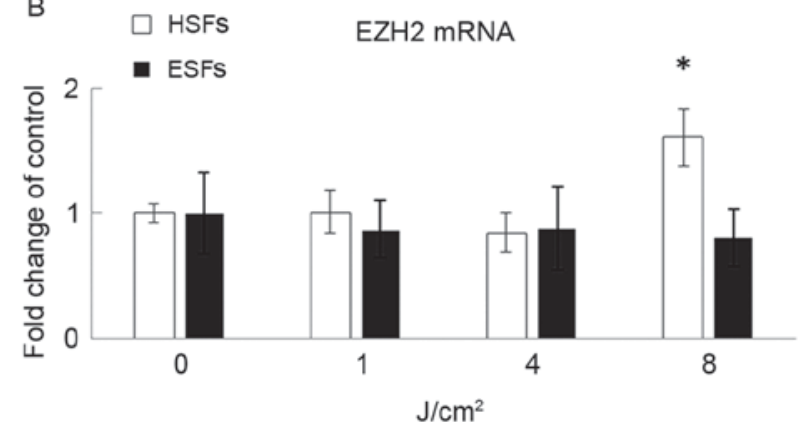

Figure 5. HSF and ESF expression of $B M I-1$ and $E Z H 2$ mRNA is modified by UVA irradiation. mRNA expression levels of (A) BMI-1 and (B) EZH2 in HSFs and ESFs irradiated with UVA. "P<0.05. HSFs, human skin fibroblasts; ESFs, embryonic skin fibroblasts; BMI-1, polycomb complex protein BMI-1; EZH2, enhancer of zeste homolog 2; UVA, ultraviolet A.

fibroblast aging. In the present study different doses of UVA radiation were applied to HSFs and ESFs in order to establish a photoaging model. Through a variety of assays, the results of the present study demonstrated that the mRNA expression levels of two genes encoding core PcG proteins, BMI-1 and EZH2, were altered in HSFs and ESFs after UVA irradiation. A similar alteration was observed in the mRNA expression of HAS1-3, HYAL1 and HYAL2. These results suggest that PcG proteins are associated with UVA-induced fibroblast aging, and may serve different roles in ESFs and HSFs.

In the dermal layer, HA serves an essential role in the aging process, and the synthesis and secretion of HA by HSFs differs at various stages of development (35). Studies investigating ESFs were first performed in regards to wound healing, in which researchers identified that adult skin typically healed through a process involving the formation of scars, whereas fetal skin did not heal through the formation of scars $(36,37)$. Multiple studies have demonstrated that this phenomenon is associated with differences in the amount of HA secreted by fibroblasts $(38,39)$. In order to explore whether the roles of PcG proteins differ in fibroblasts at various phases of development, HSFs and ESFs were chosen as cell models in the present study. The results of the present study were in agreement with previous studies, revealing significant differences in the mRNA expression levels of genes encoding key PcG proteins (BMI-1 and EZH2) between HSFs and ESFs.

The effects of UVA $\left(0,1,4\right.$ and $\left.8 \mathrm{~J} / \mathrm{cm}^{2}\right)$ on the proliferation of human fibroblasts was evaluated in the current study. The results were consistent with previous studies, demonstrating that UVA could inhibit the proliferation of fibroblasts. For example, Lan et al (40) examined the effects of UVA radiation $\left(1,3,5\right.$, and $\left.10 \mathrm{~J} / \mathrm{cm}^{2}\right)$ on the proliferation of fibroblasts using MTT. The results revealed that at $24 \mathrm{~h}$ after irradiation, the proliferation activities of cells in all groups were all decreased in a dose-dependent manner; in particular, the proliferation of cells in the $10 \mathrm{~J} / \mathrm{cm}^{2}$ group was reduced by $50 \%$ (40). Furthermore, Niu et al (41) used CCK- 8 assays to detect the effects of UVA irradiation on the proliferation activity of fibroblasts in order to investigate the underlying mechanisms of UVA-induced fibroblast photoaging. The results revealed that cell proliferation was gradually reduced on days 1,3 and 5 after irradiation (41). However, the cell proliferation rates in groups irradiated with higher doses decreased over time in a dose-dependent manner. Thus, it was speculated 
that low-dose UVA radiation may promote the proliferation of HSFs. Furthermore, the results of the present study revealed that proliferation rate of ESFs at straight after UVA irradiation was $<100 \%$, indicating that UVA irradiation inhibited cell proliferation. However, the proliferation curves increased gradually over $24 \mathrm{~h}$ after irradiation. The difference observed in the effect of UVA radiation on HSFs and ESFs may be associated with a difference in ROS production in. Under normal circumstances, a variety of antioxidant enzymes and nonenzymatic antioxidants in the human body alleviate or prevent ROS-induced cell damage; that is, ROS continuously produced in vivo are rapidly removed by antioxidant enzymes, including catalase, glutathione peroxidase or superoxide dismutase, thereby maintaining the balance between pro-oxidative and anti-oxidative factors $(42,43)$. However, when the activities of these enzymes are reduced or when an excessive amount of ROS are produced, cells may be damaged by the accumulation of ROS $(31,43)$, resulting in apoptosis, DNA damage, reduced enzyme activity, structural damage to the mitochondria and an increased rate of cellular senescence $(30,44)$. This indicates that ESFs exhibit a stronger ability to repair oxidative damage compared with HSFs, and may have increased ROS-scavenging ability, explaining the increased cell proliferation rates over time.

During the oxidative damage response in fibroblasts after UV exposure, the initiation and progression of apoptosis is significant $(45,46)$. Mirzayans et al (47) used flow cytometry to detect apoptosis in UV-irradiated fibroblasts and demonstrated that apoptosis was increased when the cells were exposed to a wide range of UVC influences (between 2 and $30 \mathrm{~J} / \mathrm{cm}^{2}$ ), and incubated for 3 or 6 days. The results of the present study revealed that the percentage of apoptotic and necrotic ESFs was increased when the cells were irradiated with UVA. However, the amount of apoptotic and necrotic HSFs were decreased after irradiation with $8 \mathrm{~J} / \mathrm{cm}^{2} \mathrm{UVA}$, contradictory to the findings of other studies (48-50). The primary factors known to induce aging include replicative aging, oxidative stress, the expression of oncogenes and the activation of DNA injury signaling pathways (51). The effects observed in the present study were speculated to be associated with the expression of oncogenes that inhibit the expression of apoptotic genes, thus enabling the cells to progress towards replicative immortality. However, further studies are required to validate this theory.

The results of HA content detection demonstrated that the HA content of HSFs and ESFs was decreased in each dose group compared with the control group, with the exception of ESFs irradiated following treatment with $1 \mathrm{~J} / \mathrm{cm}^{2}$ for $24 \mathrm{~h}$, indicating that UVA may inhibit the synthesis of HA in fibroblasts. However, differences were also observed in HA levels between the HSFs and ESFs. For example, the HA content of HSFs was notably higher compared with that in ESFs irradiated with the same dose of UVA. This observation may be associated with the sizes and polymer chain lengths of HA molecules secreted by these two cells. Previous studies have suggested that in fetal skin, HA tended to be present as high molecular weight polymers, whereas in adult skin, HA is present in various forms of different sizes $(14,52)$. This may explain why the HA content in the supernatants of cultured HSFs was significantly higher compared with that in the supernatants of cultured ESFs. The reason for this difference may also be due to variations in the level of $H A S$ and $H Y A L$ expression levels in HSFs and ESFs. The synthesis and secretion of HA in fibroblasts is dynamically regulated by HAS1-3, HYAL1 and HYAL2, among which HAS2 and HYAL1 are essential (9,53). Carre et al (14) studied the association between the expression levels of the Wnt-3a protein and HA, and examined differences in HA production between ESFs and HSFs. The results revealed that the addition of Wnt3a and TGF- $\beta 1$ induced the upregulation of $H A S 2$ and HAS3 in ESFs, and of HAS1 and HYAL2 in HSFs, further supporting the theory that there are differences in $H A S$ and HYAL expression between these two cell types. Furthermore, the RT-qPCR analysis conducted in the present demonstrated that there were differences in the expression levels of these proteins between ESFs and HSFs. In HSFs, UVA radiation induced the upregulation of HAS2,HAS3 and HYAL1, and the downregulation of HAS1. Additionally, in HSFs HYAL2 was upregulated at 1 and $4 \mathrm{~J} / \mathrm{cm}^{2}$, but downregulated at $8 \mathrm{~J} / \mathrm{cm}^{2}$. By contrast, in ESFs, UVA radiation induced the downregulation of $H A S 2$ and $H A S 3$, and the upregulation of $H Y A L 1$; HYAL2 was upregulated at $1 \mathrm{~J} / \mathrm{cm}^{2}$, but downregulated at 4 and $8 \mathrm{~J} / \mathrm{cm}^{2}$. The upregulation of HAS2 and HYAL1 in HSFs, and the downregulation of HAS2 and upregulation of $H Y A L 1$ in ESFs, may explain the markedly increased levels of HA in HSFs compared with ESFs.

Notably, the mRNA expression of HAS1 in ESFs was consistently below the minimum detection level, indicating a very low expression level of HAS1 in these cells. Consistent with this, Röck et al (17) reported that the mRNA expression of HAS2 accounted for $95 \%$ of all HAS mRNA expression, suggesting that HAS2 was the dominant enzyme among the $H A S$ family. Therefore, under normal circumstances the expression of $H A S 1$ would be $<5 \%$ of the total $H A S$ expression. Furthermore, following UVA radiation, the expression of $H A S 1$ would be expected to be reduced further, providing an explanation for the lack of HAS1 detection.

PcG proteins are epigenetic regulatory inhibitors that are associated with multiple cellular processes, including carcinogenesis, senescence, apoptosis and DNA repair (54). The majority of studies investigating PcG proteins have focused on their roles in tumorigenesis and cell senescence. Notably, EFs in BMI- 1 knockout mice enter the S phase earlier compared with those in wild-type mice, causing cell progeria; however, the target gene of $B M I-1$, the tumor suppressor gene cyclin-dependent kinase inhibitor $2 \mathrm{~A}(p 16)$, is significantly upregulated $(55,56)$. By contrast, when $B M I-1$ is overexpressed in murine EFs, the $p 16$ gene is downregulated, thereby delaying replication and senescence, and promoting replicative immortality (56). Similarly, the overexpression of BMI-1 in human fibroblasts has been demonstrated to extend the replicative life of the cells by inhibiting the p16-dependent senescence signaling pathway (57). In the present study, the expression of BMI-1 and EZH2 mRNA was examined in UVA-induced HSF and ESF aging model via RT-qPCR analysis. There were no significant differences in BMI-1 and EZH2 mRNA expression levels in ESFs in each dose group compared with the $0 \mathrm{~J} / \mathrm{cm}^{2}$ group, which demonstrated that $B M I-1$ and $E Z H 2$ didn't participate in HA regulation during UVA-induced aging ESFs. In HSFs, the mRNA expression of BMI-1 and EZH2 was upregulated after exposure to $8 \mathrm{~J} / \mathrm{cm}^{2} \mathrm{UVA}$, while the amount of apoptotic and necrotic cells were decreased at $8 \mathrm{~J} / \mathrm{cm}^{2}$. 
These results suggest that $B M I-1$ and $E Z H 2$ serve a role in HA regulation during UVA-induced aging in HSFs and also indicates that there are differences between HSF and ESF in the regulation mechanism of UVA aging. In HSFs, PcG proteins may upregulated HAS2 and HYAL1, thereby suppressing HA synthesis. However, when irradiated with higher doses of UVA, PcG proteins may be overexpressed and result in inhibition of the p16-dependent aging signaling pathway, thus promoting replicative immortality. However, further studies are required to confirm this hypothesis.

The present study had two notable limitations that affected the interpretation of the results. Firstly, changes in the expression of BMI- 1 and $E Z H 2$ were detected in the simulated photoaging cell models and indicated their participation in the aging process in fibroblasts. However, it was not examined whether these proteins function as regulatory molecules in the aging of fibroblasts. In order to investigate this concept, it will be necessary to verify the association between fibroblasts and changes in HA synthesis when BMI-1 and EZH2 are overexpressed or knocked down, and to evaluate changes in the expression of other known HA regulatory molecules during this process. Secondly, PcG proteins are comprised of a complex of a group of proteins $(58,59)$. In the present study, only the expression of two core genes of PcG, BMI-1 and EZH2 were examined, and the changes in other PcG proteins during UVA-induced photoaging were not investigated. Therefore, further studies are required to examine other members of the PcG family in order to fully identify the roles of PcG proteins in UVA-induced skin photoaging, and to distinguish epigenetic regulatory molecules and signaling pathways associated with this process. Such studies will facilitate the identification of effective targets and aid in the identifications of novel clinical treatment approaches.

In conclusion, the mRNA expression of BMI-1, EZH2, HAS2 and HYAL1 in HSFs was upregulated following high-dose UVA irradiation, suppressing HA synthesis, while cell proliferation and the amount of necrotic cells both decreased. There were no significant differences in BMI-1 and EZH2 mRNA expression levels in ESFs in each dose group compared with the $0 \mathrm{~J} / \mathrm{cm}^{2}$ group. These results suggest that $B M I-1$ and $E Z H 2$ serve a role in HA regulation during UVA-induced aging in HSFs but not in ESFs. The current study provides a new epigenetic regulatory molecule in signaling pathways of UVA-induced skin photoaging for future studies.

\section{Acknowledgements}

The present study was supported by the National Natural Foundation of China (grant no. 81372068).

\section{References}

1. Svobodová A, Psotová J and Walterová D: Natural phenolics in the prevention of UV-induced skin damage. A Review. Biomed Pap Med Fac Univ Palacky Olomouc Czech Repub 147: 137-145, 2003.

2. Sjerobabski Masnec I and Poduje S: Photoaging. Coll Antropol 32 (Suppl 2): 177-180, 2008.

3. Choi S, Youn J, Kim K, Joo da H, Shin S, Lee J, Lee HK, An IS, Kwon S, Youn HJ, et al: Apigenin inhibits UVA-induced cytotoxicity in vitro and prevents signs of skin aging in vivo. Int J Mol Med 38: 627-634, 2016.

4. Ma Y: Research progress on physiological mechanism of skin aging in plateau area. Qinghai Med J 36: 94-96, 2006
5. Young AR, Boles J, Herzog B, Osterwalder U and Baschong W: A sunscreen's labeled sun protection factor may overestimate protection at temperate latitudes: A human in vivo study: J Invest Dermatol 130: 2457-2462, 2010.

6. Morisaki N, Moriwaki S, Sugiyama-Nakagiri Y, Haketa K, Takema Y and Imokawa G: Neprilysin is identical to skin fibroblast elastase: Its role in skin aging and UV responses. J Biol Chem 285: 39819-39827, 2010.

7. Quan T, Wang F, Shao Y, Rittié L, Xia W, Orringer JS, Voorhees JJ and Fisher GJ: Enhancing structural support of the dermal microenvironment activates fibroblasts, endothelial cells, and keratinocytes in aged human skin in vivo. J Invest Dermatol 133: 658-667, 2013

8. Sparavigna A, Tenconi B and De Ponti I: Antiaging, photoprotective, and brightening activity in biorevitalization: A new solution for aging skin. Clin Cosmet Investig Dermatol 8: 57-65, 2015.

9. Wang Y, Lauer ME, Anand S, Mack JA and Maytin EV: Hyaluronan synthase 2 protects skin fibroblasts against apoptosis induced by environmental stress. J Biol Chem 289: 32253-32265, 2014.

10. Kim EJ, Kim MK, Jin XJ, Oh JH, Kim JE and Chung JH: Skin aging and photoaging alter fatty acids composition, including 11,14,17-eicosatrienoic acid, in theepidermis of human skin. J Korean Med Sci 25: 980-983, 2010.

11. Spicer AP and McDonald JA: Characterization and molecular evolution of a vertebrate hyaluronan synthase gene family. J Biol Chem 273: 1923-1932, 1998.

12. Deen AJ, Rilla K, Oikari S, Kärnä R, Bart G, Häyrinen J, Bathina AR, Ropponen A, Makkonen K, Tammi RH and Tammi MI: Rab10-mediated endocytosis of the hyaluronan synthase HAS3 regulates hyaluronan synthesis and cell adhesion to collagen. J Biol Chem 289: 8375-8389, 2014.

13. Simpson RM, Wells A, Thomas D, Stephens P, Steadman R and Phillips A: Aging fibroblasts resist phenotypic maturation because of impaired hyaluronan-dependent CD44/epidermal growth factor receptor signaling. Am J Pathol 176: 1215-1228, 2010.

14. Carre AL, James AW, MacLeod L, Kong W, Kawai K, Longaker MT and Lorenz HP: Interaction of wingless protein (Wnt), transforming growth factor-beta1, and hyaluronan production infetal and postnatal fibroblasts. Plast Reconstr Surg 125: 74-88, 2010.

15. Maeda-Sano K, Gotoh M, Morohoshi T, Someya T, Murofushi H and Murakami-Murofushi K: Cyclic phosphatidic acid and lysophosphatidic acid induce hyaluronic acid synthesis via CREB transcription factor regulation in human skin fibroblasts. Biochim Biophys Acta 1841: 1256-1263, 2014.

16. Midgley AC, Bowen T, Phillips AO and Steadman R: MicroRNA-7 inhibition rescues age-associated loss of epidermal growth factor receptor and hyaluronan-dependent differentiation in fibroblasts. Aging Cell 13: 235-244, 2014.

17. Röck K, Grandoch M, Majora M, Krutmann J and Fischer JW: Collagen fragments inhibit hyaluronan synthesis in skin fibroblasts in response to ultraviolet B (UVB): New insights into mechanisms of matrix remodeling. J Biol Chem 286: 18268-18276, 2011.

18. Cesarini E, Mozzetta C, Marullo F, Gregoretti F, Gargiulo A, Columbaro M, Cortesi A, Antonelli L, Di Pelino S, Squarzoni S, et al: Lamin A/C sustains PcG protein architecture, maintaining transcriptional repression at target genes. J Cell Biol 211: 533-551, 2015.

19. Calonje M: PRC1 marks the difference in plant $\mathrm{PcG}$ repression. Mol Plant 7: 459-471, 2014.

20. Merini $\mathrm{W}$ and Calonje $\mathrm{M}$ : $\mathrm{PRC} 1$ is taking the lead in $\mathrm{PcG}$ repression. Plant J 83: 110-120, 2015

21. Sola Y and Lorente J: Contribution of UVA irradiance to the erythema and photoaging effects in solar and sunbed exposures. J Photochem Photobiol B 143: 5-11, 2015.

22. Battie C, Jitsukawa S, Bernerd F, Del Bino S, Marionnet $C$ and Verschoore M: New insights in photoaging, UVA induced damage and skin types. Exp Dermatol 23 (Suppl 1): 7-12, 2014.

23. Niu T, Tian Y, Ren Q, Wei L, Li X and Cai Q: Red light interferes in UVA-induced photoaging of human skin fibroblast cells. Photochem Photobiol 90: 1349-1358, 2014.

24. Ryu J, Park SJ, Kim IH, Choi YH and Nam TJ: Protective effect of porphyra-334 on UVA-induced photoaging in human skin fibroblasts. Int J Mol Med 34: 796-803, 2014.

25. Min W, Liu X, Qian Q, Lin B, Wu D, Wang M, Ahmad I, Yusuf N and Luo D: Effects of baicalin against UVA-induced photoaging in skin fibroblasts. Am J Chin Med 42: 709-727, 2014.

26. Song J, Ping L, Yang Z, Li L, Su H, Lu N and Peng Z: MiR-155 negatively regulates c-Jun expression at the post-transcriptional level in human dermal fibroblasts in vitro: Implications in UVA irradiation-induced photoaging. Cell Physiol Biochem 29: $331-340,2012$ 
27. Ma HM, Tian Y, Cai Q, Liu W and Yaping E: Influences of ultraviolet radiation on the telomere length of chromosome in primary cultured human fibroblast. Lin Chuang Pi Fu Ke Za Zhi Bian Ji Bu 38: 559-561, 2009 (In Chinese).

28. Livak KJ and Schmittgen TD: Analysis of relative gene expression data using real-time quantitative PCR and the 2(-Delta Delta C(T)) method. Methods 25: 402-408, 2001.

29. Tsukahara K, Takema Y, Moriwaki S, Tsuji N, Suzuki Y, Fujimura T and Imokawa G: Selective inhibition of skin fibroblast elastase elicits a concentration-dependent prevention of ultraviolet B-induced wrinkle formation. J Invest Dermatol 117: 671-677, 2001.

30. Wang Y, Chen H, Wang W, Wang R, Liu ZL, Zhu W and Lian S: $\mathrm{N}$-terminal 5-mer peptide analog P165 of amyloid precursor protein inhibits UVA-induced MMP-1 expression by suppressing the MAPK pathway in human dermal fibroblasts. Eur J Pharmacol 734: 1-8, 2014.

31. Kretova M,Sabova L,HodnyZ,Bartek J, Kollarovic G,Nelson BD, Hubackova S and Luciakova K: TGF- $3 / \mathrm{NF} 1 /$ Smad4-mediated suppression of ANT2 contributes to oxidative stress in cellular senescence. Cell Signal 26: 2903-2911, 2014.

32. Chiang HM, Chen HC, Chiu HH, Chen CW, Wang SM and Wen KC: Neonauclea reticulata (Havil.) Merr stimulates skin regeneration after UVB exposure via ROS scavenging and modulation of the MAPK/MMPs/collagen pathway. Evid Based Complement Alternat Med 2013: 324864, 2013.

33. Wang W, Qin JJ, Voruganti S, Nag S, Zhou J and Zhang R: Polycomb Group (PcG) proteins and human cancers: Multifaceted functions and therapeutic implications. Med Res Rev 35: 1220-1267, 2015.

34. Golbabapour S, Majid NA, Hassandarvish P, Hajrezaie M, Abdulla MA and Hadi AH: Gene silencing and Polycomb group proteins: An overview of their structure, mechanisms and phylogenetics. OMICS 17: 283-296, 2013.

35. Lee BM, Han DG and Choi WS: Rejuvenating effects of facial hydrofilling using restylane vital. Arch Plast Surg 42: 282-287, 2015

36. Mast BA, Haynes JH, Krummel TM, Diegelmann RF and Cohen IK: In vivo degradation of fetal wound hyaluronic acid results in increased fibroplasia, collagen deposition, and neovascularization. Plast Reconstr Surg 89: 503-509, 1992.

37. Estes JM, Adzick NS, Harrison MR, Longaker MT and Stern R: Hyaluronate metabolism undergoes an ontogenic transition during fetal development: Implications for scar-free wound healing. J Pediatr Surg 28: 1227-1231, 1993.

38. Shibata S, Cho KH, Kim JH, Abe H, Murakami G and Cho BH: Expression of hyaluronan (hyaluronic acid) in the developing laminar architecture of the human fetal brain. Ann Anat 195: 424-430, 2013.

39. Olutoye OO, Barone EJ, Yager DR, Uchida T, Cohen IK and Diegelmann RF: Hyaluronic acid inhibits fetal platelet function: Implications in scarless healing. J Pediatr Surg 32: 1037-1040, 1997.

40. Lan CC, Ho PY, Wu CS, Yang RC and Yu HS: LED $590 \mathrm{~nm}$ photomodulation reduces UVA-induced metalloproteinase-1 expression via upregulation of antioxidant enzyme catalase. J Dermatol Sci 78: 125-132, 2015.

41. Niu T, Tian Y, Cai Q, Ren Q and Wei L: Red light combined with blue light irradiation regulates proliferation and apoptosis in skin keratinocytes in combination with low concentrations of curcumin. PLoS One 10: e0138754, 2015.

42. Svobodová A, Walterová D and Psotová J: Influence of silymarin and its flavonolignans on $\mathrm{H}(2) \mathrm{O}(2)$-induced oxidative stress in human keratinocytes and mouse fibroblasts. Burns 32: 973-979, 2006.
43. Svobodová A, Zdarilová A, Walterová D and Vostálová J: Flavonolignans from Silybum marianum moderate UVA-induced oxidative damage to HaCaT keratinocytes. J Dermatol Sci 48: 213-224, 2007.

44. Mattson MP, Gary DS, Chan SL and Duan W: Perturbed endoplasmic reticulum function, synaptic apoptosis and the pathogenesis of Alzheimer's disease. Biochem Soc Symp: 151-162, 2001.

45. Debacq-Chainiaux F, Borlon C, De Hertogh B, Remacle J, Morvan PY, Vallée R and Toussaint O: Identification of potential anti-photoageing algal compounds using an in-vitro model of photoageing. J Pharm Pharmacol 58: 1577-1583, 2006.

46. Chainiaux F, Magalhaes JP, Eliaers F, Remacle J and Toussaint O: UVB-induced premature senescence of human diploid skin fibroblasts. Int J Biochem Cell Biol 34: 1331-1339, 2002.

47. Mirzayans R, Scott A, Andrais B, Pollock S and Murray D: Ultraviolet light exposure triggers nuclear accumulation of p21(WAF1) and accelerated senescence in human normal and nucleotide excision repair-deficient fibroblast strains. J Cell Physiol 215: 55-67, 2008.

48. Anitua E, Pino A and Orive G. Plasma rich in growth factors inhibits ultraviolet B induced photoageing of the skin in human dermal fibroblast culture. Curr Pharm Biotechnol 17: 1068-1078, 2016.

49. Zhang C, Wen C, Lin J and Shen G: Protective effect of pyrroloquinoline quinine on ultraviolet A irradiation induced human dermal fibroblast senescence in vitro proceeds via the anti-apoptotic sirtuin 1 /nuclear factor-derived erythroid 2 related factor $2 /$ heme oxygenase 1 pathway. Mol Med Rep 12: 4382-4388, 2015.

50. Wang H, Shang L and Hao W: The induction of apoptosis and reactive oxygen species in human skin fibroblast by ultraviolet A. Beijing Da Xue Xue Bao 35: 69-73, 2003.

51. Zhou BR, Guo XF, Zhang JA, Xu Y, Li W, Wu D, Yin ZQ, Permatasari F and Luo D: Elevated miR-34c-5p mediates dermal fibroblast senescence by ultraviolet irradiation. Int J Biol Sci 9: 743-752, 2013.

52. Tolg C, Telmer P and Turley E: Specific sizes of hyaluronan oligosaccharides stimulate fibroblast migration and excisional wound repair. PLoS One 9: e88479, 2014

53. Midgley AC, Rogers M, Hallett MB, Clayton A, Bowen T, Phillips AO and Steadman R: Transforming growth factor- $\beta 1$ (TGF- $\beta 1$ )-stimulated fibroblast to myofibroblast differentiation is mediated by hyaluronan (HA)-facilitated epidermal growth factor receptor (EGFR) and CD44 co-localization in lipid rafts. J Biol Chem 288: 14824-14838, 2013.

54. Terranova R, Yokobayashi S, Stadler MB, Otte AP, van Lohuizen M, Orkin SH and Peters AH: Polycomb group proteins Ezh2 and Rnf2 direct genomic contraction and imprinted repression in early mouse embryos. Dev Cell 15: 668-679, 2008.

55. Haupt Y, Bath ML, Harris AW and Adams JM: Bmi-1 transgene induces lymphomas and collaborates with myc in tumorigenesis. Oncogene 8: 3161-3164, 1993.

56. Jacobs JJ, Kieboom K, Marino S, DePinho RA and van Lohuizen M: The oncogene and Polycomb-group gene bmi-1 regulates cell proliferation and senescence through the ink4a locus. Nature 397: 164-168, 1999.

57. Itahana K, Zou Y, Itahana Y, Martinez JL, Beausejour C, Jacobs JJ, Van Lohuizen M, Band V, Campisi J and Dimri GP: Control of the replicative life span of human fibroblasts by p16 and the polycomb protein Bmi-1. Mol Cell Biol 23: 389-401, 2003.

58. Rajasekhar VK and Begemann M: Concise review: Roles of polycomb group proteins in development and disease: A stem cell perspective. Stem Cells 25: 2498-2510, 2007.

59. Simon JA and Kingston RE: Mechanisms of polycomb gene silencing: Knowns and unknowns. Nat Rev Mol Cell Biol 10: 697-708, 2009. 